\title{
Maa ja avaruus Lauri Viljasen runoudessa
}

Aikakauslehti Nuoren Voiman avustajiin liittyi vuodesta 1919 alkaen nuori kynänkäyttäjä, joka varhaisten runojensa alle piirsi salaperäisen nimimerkin "Acerbus". Kolme vuotta myöhemmin nimimerkillä oli jo niin paljon runoja pöytälaatikossaan, että hän suunnitteli oman kokoelman julkaisemista. Lehden toimitus näet tiedotti painattaessaan vuonna 1922 runon "Suven sineen", että näyte oli aiotusta esikoiskokoelmasta Multa ja sini. Tällaisenaan kokoelma ei tosin koskaan ilmestynyt, mutta nimi oli joka tapauksessa enne. Nimimerkki Acerbus, runoilija Lauri Viljanen, oli jo tuossa varhaisessa vaiheessa kartoittanut tulevan lyriikkansa sekä maisemalliset että maailmankatsomukselliset ääripisteet. Multa ja sini - maa ja avaruus — ovat ne toisistaan etäiset kohteet, jotka hänen symbolikielessään saavat niin merkityspitoisen ajatussisällön. Tämänkertaisen tarkastelijan keksintö ei ole uusi. Melkein kaikki Viljasen runouden tutkijat ovat kiinnittäneet siihen huomiota, ja selvimmin sen tulkitsee Unto Kupiainen esitellessään kokoelmaa Näköala vuorelta: "Samalla kun Viljasen symboliikassa maan mullalla ja siitä juurin voimaa juovilla puilla yhä edelleen on keskeinen sijansa, valtaavat tuuli, ilma, pilvet ja valo omalaatuisella tavalla paikan hänen runojensa vertauskielessä." ${ }^{1}$ Kaarlo Marjanen taas toteaa esitellessään Viljasen runouden keinoja ja ratkaisuja, että näiden lyyristen ydinsymbolien ympärille muodostuva runous on yllättävän yhtenäinen. ${ }^{2}$ Runoilijan uskollisuus vertauskuvien valinnassa näkyy vielä tähän asti viimeisessä kokoelmassa Seitsemän elegiaa. Huomattakoon eri-

${ }^{1}$ Unto Kupiainen, Lauri Viljanen lyyrikkona. Suomalaisen kirjallisuuden vuosikirja 1947. Porvoo 1947, s. 255.

${ }^{2}$ Kaarlo Marjanen, Viljasen lyriikan keinoja ja ratkaisuja. Kirjallisuudentutkijain seuran vsk. 18. Porvoo 1960, s. 215. 
tyisesti sellaiset jo nimissäänkin kuvaan kiinnittyvät runot kuin "Puille" ja "Pilvet". Elämänkokemusten avartama maailmankuva on jälkimmäisessä huikaistunut äärettömyyksiin:

Pilvet kulkevat ylitse kaupungin välillä maan ja taivaan lainehtien vasten maailman ääriä, niin liki, ettei lomasta lentää voi edes kaipuun lintu.

Esikoiskokoelmassaan Auringon purjeet Lauri Viljanen on vielä "onnen poika" maatessaan ruohikossa maan povella ja kuunnellessaan miten "tuuli pitkän riemusäveleen/pihkanpunertaviin oksiin soittaa". ("Metsässä.") ${ }^{3}$ Mullan läheisyys lämmittää Viljasen nuoruudenkokoelmissa "maan poikaa", joka näkee kylväjän työn siunautuvan. Maasymboliikalla on toisinaan suorastaan sakraalinomainen pyhyys, jonka alkuperä on helposti johdettavissa uskonnollisen kodin antamista herätteistä. Hedelmällinen multa vangitsee runoilijansa niin kiinteästi, että huolimatta rauhattomasta kaipauksestaan hän tuntee olevansa olennainen osa maan rikkaudesta. Suorastaan ohjelmallisena nuoren Viljasen järkkymätön usko maahan selittyy runosta "Gaia", josta käsin Kupiainen on saanut aiheen puhua "Gaiapiirteestä", maantunteesta, joka läpäisee koko Viljasen runouden." "Gaia"-runossa maata verrataankin elämän sydämeen, joka alituisesti pystyy uudistamaan luonnon. Nuoruudenpessimismin ja levottoman kaipauksen hajottama runoilija tuntee maan poikana olonsa turvalliseksi:

Sa uhmaat talven pakkasta ja jäätä, sun povessashan kevät uinuu uus: sun poikanas en sure päiväin päätä, on suvi kypsynyt jo ikuisuus.

Oi milloin täyden, rikkaan rauhas tapaan, sä uskollinen sydän elämän, niin että viestis, lempeän ja vapaan, voin laulaa yli ajan myrskyisän?

Maa kukkivana ja hedelmällisenä symbolisoi Viljaselle myös rikasta ja harmonista ihmiselämää. Maan tapaan runoilijakin pyr-

${ }^{3}$ Runositaatit on lukuunottamatta Seitsemän elegian runoja otettu Viljasen Kootuista runoista. Porvoo 1946.

4 Kupiainen, m. kirj., s. 246. 
kii uudistumaan, hänelle maa jatkuvassa luomiskyvyssään on esikuvallinen. ${ }^{5}$ — Näissä ensi kokoelman aikaisissa tunnoissaan kiinteästi maan povella elävän runoilijan mielikuvissa avaruuden symboleista vain auringolla on keskeinen ja tärkeä elämää luova voima. Tuuli koetaan ohimenevästi. Kaukaisen tuulen havina kuuluu vaimeana, vilvas tuuli kohtaa runoilijan kasvot, lempeä tuuli hengittää tai ajaa pilviä. Se on vain luonnonvoima, elementti, joka kuuluu osana kosmokseen. Siihen ei vielä sisäisty mitään, se on runoilijalle ulkokohtainen.

Tähtikeinun runoilija etääntyy jo maan turvallisesta kamarasta ja valloittaa koko avaruuden rakkautensa ilmakehäksi:

Keinu heilahda taivainen pitkin hiljaista Linnunrataa!

Usmat yöllisen korkeuden unhon valkeaa härmää sataa...

Maasta irtautuva vapautuneisuus ei kuitenkaan vielä tässä kokoelman nimirunossa pyrikään olemaan pysyvää. Palataan takaisin maan pinnalle: "Armas, muistatko kyynelin / keinun vaahterapuiden alla _ ?" Avaruudellisista symboleista hallitsevat kokoelmaa "hiilenmusta" taivas ja tähdet, jotka ovat "kuumia", "huikaisevia", "kultaisia". Vertauskuvat ovat siis vielä kiinteitä, ne eivät leijaile tuulen tai pilvien tapaan runon mukana. Viljasen emotionaalisissa nuoruuden rakkauslauluissa riittää tunteenomainen kokemus huikaisevan avaruustunnelman nousuun. Rakastettu ja rakastuneen nuorukaisen oma tunne kantavat laulun kohti tähtikirkkaita avaruuksia. Kokoelmassa on jo kuitenkin ääniä siitä urkumusiikin sävyttämästä humisevan avartuneesta ihmisyyden julistuksesta, joka myöhemmin tulee niin leimalliseksi Viljasen lyriikassa.

Äärettömyyksiin kurkottuva luonnontunne, joka kuitenkin hakee kiinnityskohtia maasta, liittyykin usein Viljasen humaniteettiajatukseen, kaikkeutta syleilevään maailmankatsomukseen. Mustasta runottaresta lähtien, joka on monessakin suhteessa runoilijansa kypsymistä osoittava, alkaa esiintyä yhä merkitsevämmissä yhteyksissä symbolikuvia "mullan ja sinen" väliltä. Tästä alkaen voidaan myös puhua Viljasen lainehtivasta runoudesta. Lyyrikko hakee yhdyssidettä maan

\footnotetext{
s Veija Marjanen, Lyyrikon keskipäivä. Aineksia Lauri Viljasen runoilijakuvaan. Suomalainen Suomi 1941, s. 154.
} 
ja avaruuden välille. Ambivalenttisen pyrkimyksensä näihin kumpaankin, rakkauden maahan ja kaipauksen siitä ylös, hän tunnustaa Näköala vuorelta-kokoelman "Laulussa suvipilvelle":

\section{Maata rakastat, tummaa, pientä maata. \\ Sentään vangita ei maa jalkaas saata, henki siintävän häivän, autuus nousemisen!}

Viljasen runoudessa on jo varhain havaittavissa muuan keino kokea "nousemisen autuus". Se on korkeiden näköalapaikkojen, avarien horisontaalisten piirien tavoittelu. Varsinkin suurissa tilitys- ja julistusrunoissa tämä pyrkimys korostaa myös sisäistä avartuneisuutta. ${ }^{6}$ Jo ensi kokoelman runossa "Kevättalvi" "mua aurinkoon, mua vuoren kukkulalle/tie halki maaliskuisen metsän toi". Sama korkea näköala sekä maisemallisessa että maailmankatsomuksellisessa mielessä on "Nuoren Prometheuksen" kolmannessa runossa "Pyökit ja tammet": "Katselin kauan / vuorilta vuosien kiertoa: / vanhojen pyökkien alla / on paljon kuolleita lehtiä!" - Myös ne rakkaudella luodut kotiseudun "laajojen tasankojen" kokonaisvaltaiset kuvat, joita on niin runsaasti Viljasen lyriikassa, antavat mielikuvan korkean näköalapaikan tähystyspisteestä. Tässä yhteydessä on aiheellista muistaa, että useat tutkijat ovat saaneet lähtökohtia päätelmiinsä Viljasen nuoruudenmieltymyksestä Giacomo Leopardin runouteen. Viljanen ei itsekään ole kieltänyt tämän lähtökohdan todenperäisyyttä. Uskollisuus nuoruuden suureen ihanteeseen on Viljasen esseetaiteessa vielä vuosikymmeniä myöhemmin pukeutunut ymmärtämyksellä ja ihailulla piirrettyyn muotokuvaan tuosta italialaisesta maailmantuskan runoilijasta, jota hän jo kouluaikanaan kertoo rajattomasti ihailleensa. Kiinnostus ja ihailu veivät hänet 1950-luvun loppupuolella myös Leopardin kotiseudulle Recanatiin. "Meidän herkimmät ja kestävimmät vaikutelmamme lyriikan mestareista liittyvät epäilemättä nuoruuden päiviin", Viljanen tunnustaa esseessään. Nuoren turkulaisen koulupojan silmiin ei ehkä Kaarinan metsäisillä kukkuloilla ole puuntanut niin äärettömiä näköaloja kuin Leopardilla

- Aili Luotola, Lauri Viljanen lyyrikkona. Laudaturkirjoitus. Helsinki 1954, s. 53 .

${ }^{7}$ Lauri Viljanen, Maailmantuskan runoilija. Illan ja aamun välillä. Helsinki 1941, s. 169. 
Recanatissa: "Laakso alla aaltoaa vihreänä merenä ja yhtyy taivaan rantaan. Avaruuden tunto on ihmeellinen."s Voinemme silti kuvitella nuoren Viljasen askelten usein vieneen Kaarinan vielä hänen nuoruudessaan harvaan asutuille kummuille, joita hän varhaisissa maalauksissaan vangitsi myös kankaalle, ja silmäilleen sieltä "yli tasankojen". Tätä Viljasen lapsuudenmaiseman kumpuilevaa maastoa on Veija Marjanen kuvaillut eräässä kirjoituksessaan silmin nähtävän havainnollisesti. ${ }^{9}$ Nuori, runoutta harrastava koulupoika sai ehkä näiltä vaatimattomilta näköalapaikoilta todellisuudenvastiketta Leopardin-ihailulleen, ensimmäisen kosketuksen niihin avaruudentuntoihin, jotka myöhemmässä lyriikassa paisuvat niin äärettömiksi. - Pyrkimys laajoihin kokonaisvaltaisiin näkymiin on epäilemättä antanut Viljaselle oman lyriikan rinnalla myös kyvyn ja mieltymyksen tulkita samankaltaisia tuntoja maailmanlyriikkaa suomentaessaan. Alfred de Vignyn runossa "Mooses" Viljanen on tavannut mahtavan ilmaisun äärettömille näköaloille. Jumalan mies katselee Neebon vuorelta "pois yli näköpiirin avaran" ja tavoittaa silmillään luvatun maan, johon hän ei koskaan itse ole pääsevä.

Leopardin korkean näköalapaikan maisemaluonne ja äärettömyyden mielikuva kuultaa selvemmin Viljasen runossa "Näköala vuorelta", jossa monet yksityiskohdatkin kertovat alitajuisesta suuresta lyyrisestä nuoruuden elämyksestä:

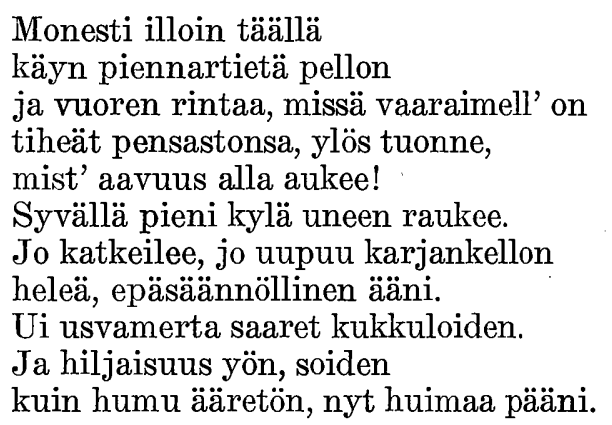

Tässä runossa valahtaa jo ikuisuuden tuntoa avartuvaan näköalaan: mennyt ja tuleva, syvä hiljaisuus ja resignaatio sulautuvat

${ }^{8}$ Elsa Tervo, Leopardin Recanatissa. Esipuhe Leopardin lauluihin. Jyväskylä 1962, s. 12.

9 Veija Marjanen, m. kirj., s. 154. 
äärettömyyden huminaan. Kaarlo Marjanen on kiinnittänyt huomiota Viljasella usein esiintyvään musikaaliseen sanaan "humina", joka muovautuu lukemattomiin eri asuihin. ${ }^{10}$ Tuulikin, joka nuorella lyyrikolla on vielä "vilvas", muuttuu keski-ikään tultaessa "humisevaksi". "Näköala vuorelta" on syvästi elämänkatsomuksellinen runo, jossa koko olevaisuus humisee äärettömyyttään, päätä huimaavana. Se on pilvien aaltoilua korkealla taivaalla, mutta se kätkeytyy myös runoilijan sisimpään: "Omassa maailmassaan sydämellä / nyt avaraa on olla."

Vapaan Iuonnonläheisen näköalapaikan korvaa Viljasen lyriikassa joskus myös korkean kivitalon ikkunasta avautuva laaja näkymä. S'eitsemän elegian runo "Pilvet", jonka "maisema", katunäkymä kirkkoineen, lienee saanut alkunsa myöhemmällä Turun kaudella, ei enää sisällä yksinomaan resignaatiota, vaan myös epävarmuutta elämän tarkoituksesta. Tässäkin voitaisiin puhua Viljaselle ominaisesta lainehtivasta runosta, maan ja avaruuden välisessä tyhjiössä leijuvista mielikuvista. Runoilija näkee korkealta näköalapaikaltaan "matalia, korkeita taloja, maahan / juurtuneina kaikki turvallisesti, / mutta pilvet, pilvet vaeltamassa/kuin ne, joilla ei ole varmuutta mistään". Kirkon torni nousee iäisyyttä tavoitellen huipentuvin kiiloin kohti olemattomuutta "kiinnittääkseen ihmisten kamaran ikivanhaan nimeen taivas". Tällä kerralla maan turvallisuus ei kuitenkaan ole lohduttavaa. "Ainoa koti on välillä, varmuus, jota / tyhjän varassa kantaa pilven siipi."

Seitsemän elegian laaja meditoiva runo on myös muodollisesti erityisen mielenkiintoinen. Se on omalaatuinen yhdistelmä staattista paikallaan pysymistä ja vinhaa kiitoa. Maan kamaralla tukevasti seisova kirkontorni ja talot, runoilijan hievahtamaton asento ikkunan ääressä kuvastavat staattista paikoillaan pysymistä. "Kiireetöntä on ikkunan ääressä yksin/katsoa suoraan vaiteliaihin pilviin." Liikkumattomuuden vastapainoksi tuodaan runoon alhaalla maan pinnassa viittoillen ja puhellen rientävät ihmiset, "tumman maan ja heleän ikuisuuden" välillä lainehtivat pilvet. Ne antavat liikettä etenevään suuntaan, ja kolmasti toistettuna säe "pilvet kulkevat ylitse kaupungin" korostaa tehokkaasti tapahtuvaa kulkua. Kaarlo Marjanen mainitsee itävaltalaisen runoilijan Josef Weinheberin analysoi-

${ }^{10}$ Kaarlo Marjanen, m. kirj., s. 212. 
dessaan Viljasen runoa "Lumisade" ja toteaa kummallakin lyyrikolla olevan samantapaisia pyrkimyksiä etenevän ja paikoillaan pysymisen tasapainottamiseksi. ${ }^{11}$ Kysymys on lähinnä lyyrisestä muodontoteutuksesta. Seitsemän elegian pilvinäkymässä runoilija tuntuu miettineen juuri seisahtuneen ja kiitävän samanaikaista vangitsemista runoonsa.

Jylhimmän mielikuvan korkean näköalapaikan vertauskuvallisuudesta Viljanen antaa aaterunoelmassaan Atlantis, jossa vuoren huipulla asustava tyrannimainen valtias tuhoaa elämää mielensä mukaan. Lukijalle ei tässä kuitenkaan välitetä Viljaselle ominaista sisäisen avaruuden tajua, vaan pikemminkin pohjattomien kuilujen pelottavia näkymiä.

Viljasen pyrkimystä toisaalta maan lujaan kamaraan, toisaalta ylös huimaaviin avaruuksiin symbolisoivat puut, joiden vertauskuvallisuuden tutkijat ovat oivaltaneet. Runoilija on itsekin viime kokoelmassaan myöntänyt avoimin säkein mieltymyksensä noihin ajattomuutta kantaviin pylväisiin. "Puille"-runon reaalinen maisema lähelle taloa "vuosien mennen" kasvaneine puineen, ohijyskyttävine junineen ja ylhäällä taivaalla pauhaavine vuorokoneineen on helposti tunnistettavissa runoilijan kesäasunnon maisemaksi. On käsillä elonkorjuun aika, joka vie keskipäiväänsä elävän lyyrikon ajatukset entiseen:

Puut kauniit, ajalla ilon ja murheen kenties ylenmäärin ylistin teitä ja lausuin, aavistamattani, joskus salaloitsun, mahtavan taikasanan? Olen veljeksenne sieluni tehnyt. Elän hiljaisuutenne pitkää aikaa kysymättä, unhonkypsänä, milloin voi syksyni viimein saapua maille. Kuin nyt, valo hiljaisuutta on silloin ja hiljaista lehtien putoaminen yli erään: tomun vain, joka jäi jo nimeä vaille.

Jo aikaisemmin runossa "Ex dolore amor" puusymboliikka kasvaa voimakkaasta yhteenkuuluvuudesta ja yhteiskohtalosta elämän

11 Kaarlo Marjanen, m. kirj., ss. 218—219. Vrt. myös Josef Weinheber, Ưber die Dichtkunst. Zürich 1949, s. 61. 
maanläheisyyteen, ja samantapaisen samastumisen tekijä kokee runossaan "Puut keväällä":

Sieluni voimassa

jokin on sukua teille. Vastustamaton

kaipaus vetää minua puoleenne.

Näistä tunnustuksenluonteisista säkeistä huomaa helposti, että puuaiheiden runsas käyttäminen on Viljasella tietoisen tarkoituksellista tai — niin kuin hän itse sanoo - vastustamattoman kaipauksen sanelemaa. Puut korkealle pyrkivässä nousussaan symbolisoivat hänelle ikuisempia arvoja kuin pienet ihmiset, jotka häärivät nüiden juurella. ${ }^{12}$ Sama vaisto, joka ajaa runoilijan korkeille näköalapaikoille, saa hänen kaipauksensa nousemaan puusymboliikassa mullasta pilviin ja sineen. Ambivalenttinen pyrkimys toisaalta maan hedelmälliseen multaan, toisaalta huikaiseviin äärettömyyksiin yhdistää sielunelämän dualismia, ja puuaiheet kasvavat tätä dualismia yhdistäväksi tekijäksi. ${ }^{13}$ Erkki Rantalainen on analysoidessaan Viljasen filosofista runoilijaluonnetta päätynytkin kaksi-ilmeisiin Januksen-kasvoihin, joista näkyy sekä elämä maan mullassa että ihmishengen ajaton pyrkimys ikuisuuteen. ${ }^{14}$ Vastakohta-asettelut eivät kuitenkaan Viljasen lyriikassa koskaan ole sovittamattomia. Valo ja varjo, elämä ja kuolema, maa ja avaruus, maanläheinen ja sinenkaukainen, tumma ja vaalea pyrkivät sulautumaan yhdeksi kosmiseksi näyksi. Puissa yhdistyy jo sinänsä elämän ja kuoleman ikuinen vuorovaikutus. Lyyrikko kokee sen myös itsessään runossa "Puut syysvalossa":

Puut korkeat, kanssanne elänyt

olen monta kuolemaa.

Mutt' aamunsa valossa, tunnen nyt, sydän alati vaeltaa.

Kenties puhuvimman ilmaisun halustaan kasvaa "kohti ikuisuutta" Viljanen on puusymboliikkansa valossa luonut runossaan "Puut keväällä":

12 V. A. Koskenniemi, Lauri Viljanen: "Kootut runot". Kootut teokset VIII. Porvoo 1955, s. 588.

${ }^{13}$ Luotola, m. laudaturkirj., s. 82.

${ }^{14}$ Erkki Rantalainen, Lauri Viljasen runoilijaluonne. Nuori Suomi 49 (1939), s. 74 . 
Odottavat, hartaat, liikkumattomat, vaikenevat, kaltaisenanne keväästä kevääseen alati sieluni kasvaa tahtoi, arpisin juurìn syvältä elämänmullan muodottomasta pimeydestä juoden, mutta autuas latva kurkoittuneena valoa kohti ylimaallista, tuntematonta kuin ikuisuus!

Viljanen on puusymboliikassaan yhdistänyt julkaisemattoman esikoiskokoelmansa kalssi ääripistettä, mullan ja sinen. Ikuisuuden tavoittaminen, autuas nouseminen, sinen kokeminen ei kuitenkaan tuota pysyvää tyydytystä. Puusymboliikkaan tulee myöhemmin paikoin elämänkokemusten tuomaa hyvinkin kitkerää tuhkanmakua. Seitsemän elegian "Vuorolaulussa" kirjavien lehtien hehku on turhuutta: "Kohotan palvoen huurteista latvaa, / mutta ei sula runkoni routa." Vuodenaikojen hyökyä vasten piirtyy paljas pilari, joka ei enää tunne tuulen huminaa lehvistössään: "Tuuli enää, ei enää/koskaan tartu näihin / valtaoksiini arpisiin, / jotka ilmojen otteessa kerran / lauloivat niinkuin kantele!" Viljasen keskeisimpään vertauskuvaan on tullut ankaruutta, joka karsii siitä kaiken epäoleellisen.

Tuuli onkin Viljasen runouden merkitsevimpiä avaruussymboleja. Se humisee ikuisuutta puiden latvoissa runossa "Tuuli ja ihminen":

Tule, sieluni: kaukaisiin ma kaipaan, katsoa halaan, miten elävät ihmiset. Ylös, lähdemme vaeltamaan!

Ajat, paikat ihmeelliset ovat jääneet meiltä salaan.

Tule, iätön tuuli on ne nähnyt matkallaan.

Ei askelta vapaampaa, ei niin ilonkevyttä mitään.

Se on naurua tähden tään, kevätmyrsky lännestä itään ja pohjasta etelään ja vaiheilla taivaan ja maan.

Riemullinen matkanteko tuulen mukana laventaa horisontaalista tasoa, kaikki maat tulevat lähemmäksi ja "tämä tähti", maa, muuttuu mittasuhteiltaan. Mutta tuuli antaa runoilijalle myös Ikaroksen sïvet, se vie ajattomuusmatkalle, ${ }^{15}$ nostaa runon vertikaalista tasoa,

${ }^{15}$ Luotola, m. laudaturkirj., s. 75. 
korkealle ylös avaruuteen, jossa kaikkeus ottaa syliinsä. "Ei orpoa kohtaloaan sydän kuuntele kohussa tuulen: / tämä laulu on kaikkien, sävel mahtava veljeyden."

Tuuli on Viljasen symbolikielessä perin moniselityksinen. Nuoruudentuotannon mullanläheisessä rauhassa se täydentää syvää tyytymystä maanyhteisyyteen. "Metsässä"--runon onnenpoika kuuntelee ruohikossa maatessaan tuulen syvää tuutulaulua huojuvien mäntyjen latvuksissa. Samassa runossa tuulella on riemukasta onnentunnetta kuvaava merkitys. Runoilija puhuu myös "elävästä tuulesta", joka ottaa aktiivisesti osaa maisemanmuodostukseen. "Kuuma tuuli" symbolisoi elämää, joka pyörremyrskyn tavoin tempaa ihmisen mukaansa. Runossa "Rakkaus vainoaikaan" tuulella on viestintuojan rooli: "Yö tummuu, myrsky tuulee, / yli maailman suuria sanoja tuo." Samanlainen uhkaava sodan viesti on sillä "pakkastuulella", joka runossa "Vanhukset" tunkeutuu kahden vanhan ihmisen lämpimään tupaan. Sodan tuomaa lopullista rauhaa, johon liittyy myös syvä suru, on tuulen huminassa "Suruhymnissä kaatuneille":
Vaiheilla kirkkomaiden valkean muurin on syvä sointu tuulessa keväimen. Surua, kunniaa soi lauluista suurin, musiikki tumma kotimme ikuisen.

Samassa runossa kuullaan sitten vihdoin tuulen soitossa se ikuisuuden humina, johon Viljanen päätyy tuulisymboliikassaan: "Soi kevättuulen laulu hautojen päällä, / soi sävel yhteen elämän, kuoleman." Tuuli muuttuu kaikkeuden huminaksi, joka "Puut"-runossa on nimen omaan "mahtava". "Tuulessa ja ihmisessä" ihmissydän on rauhattomuudessaan tuulen kaltainen ja "käy välillä taivaan ja maan humu loputon huokausten".

Pilvet kuvastavat samalla tavalla milloin runoilijan mielentilaa, milloin ikuisuustuntoja. Seitsemän elegian runossa "Pilvet" nuoruudenmuistoja symbolisoivat poutapilvet, kevyet iloiset viirit, jotka kantavat "tumman maan ja heleän ikuisuuden" välille. Sota-ajan tunnelmia kuvastavat levottomasti kiiruhtavat pilvet "Sotilaan hautauksessa". Ylös siintäviïn korkeuksiin laulu nousee pilven tapaan ikuisuustunnoiltaan ylevässä "Laulussa suvipilvelle":

Kauas veljesi jäävät. Menkää, menkää!

Haipuu vihreys maan, vain tuuli henkää kaikkeushengähdyksin rintaasi koskettain. 
Riemu tumma on mullan, kirkas sinen.

Kauas on kaipuu, huimaus ihmeellinen -

lähellä tähtiä yksin,

yksin ylhäällä vain!

Lauri Viljasen avaruussymbolien esittelyssä ei ole syytä unohtaa sitä merkitystä, joka valolla on hänen vertauskuvallisessa ilmaisussaan. Kuinka läheiseksi Viljanen on tuntenut itselleen sen "puhtaan valon ikuisuuden", josta hän puhuu esitellessään Paul Valéryn lyriikkaa Taistelevassa humanismissaan, sen voi lukija todeta hänen runoudestaan. Kuultavassa valossa kuvastuu ikuisuusarvoja. Kaikki hyvä ja kaunis kietoutuu valon läpikuultavaan verhoon, muuttuu kokonaan valoksi. Runossa "Kotiseutu" lapsuudenmuistot hohtavat puhtaassa valossa: "Valoa täällä on kaikki: / tumma, pieni / kirkkotarha valoa täynnä on." Valon vertauskuvallisuutta selventää ilmaisuvoimaisimmin runo "Valonpeittämä laiho", jossa siinäkin Viljanen suorittaa retrospektiivisen elämäntilityksen. ${ }^{16}$ Viljavainion yllä väreilee se "lyyrinen ilmakehä", se multa, josta runoilija korjaa oman satonsa:

En herra tämän vainion, en täällä

ma ollut kyntäjä, en kylvömies.

Omaani on vain valo tähkäin päällä,

ja sieltä korjaan lyhteeni kenties.

Samaan ajattomuuden peltoon suorittaa kylvötyönsä V. A. Koskenniemen "Kurkiauran" kylväjä: "Sato muiden mullassa itää, / mut ilmassa runoilijain."

Pyrkimys tuulen, ilman, valon puoleen saa Viljasen runoudessa, erityisesti puusymboliikassa, lisämerkitystä siitä, että vaikka puu imee elämänravintonsa syvältä maan mullasta, sen elämänilo huipentuu ylhäällä avaruudessa. Jo Tähtikeinun aikoihin Viljanen pyrki siirtämään todellisuuden rajat entistä kauemmaksi ja luomaan "maailman ulkopuolelle maailman". ${ }^{17}$ Myöhemmin tuo maailma ulkopuolella maailman saa ikuisuustunnoiltaan vielä kuulaamman merkityksen. Hellittämätön pyrkimys korkeille näköalapaikoille, runokuvien hakeutuminen avaruudellisiin symboleihin on kaikki siirtymistä sisäis-

16 Unto Kupiainen, Suomalainen lyriikka Siljosta Sarkiaan. Porvoo 1948, s. 276 .

17 T. [Vaaskivi], Kuusi suomalaista runoilijaprofiilia Kretsehmerin typologian valossa. [Kirj.] T. Wahlsten. Nuori Suomi 45 (1935), s. 99. 
tyneeseen, lainehtivaan avaruuteen ja puhtaan valon ikuisuuteen. Runojen rytmikin muuttuu toisinaan niin kevyen lainehtivaksi, että runo voi pilven tavoin pysytellä ilmassa "tumman maan ja heleän ikuisuuden" välillä. Multa, elämää säilyttävä ja kasvattava multa, on kaiken perustana, mutta lyyrinen sato korjataan avaruudessa.

\section{KERTTU TANNER: Earth and space in the poetry of Lauri Viljanen}

The lyrical works of the poet Lauri Viljanen contain a consistent group of symbols, the development of which can be traced from his early works onwards. Belief in the soil is a dominating influence in the works of his youth, where the power of a religious home is inextricably interwoven with a genuine holiness.

The most evident expression of the young Viljanen's belief in the soil is to be found in the poem "Gaia", which leads Unto Kupiainen, a student of Viljanen's works, to speak of the relation to the Gaia of classical legend, the personification of the earth, which runs right through Viljanen's poetry. From this personification a certain tree symbolism springs and becomes central.

From his third collection of poems (Musta runotar) onwards, wind, air, light and clouds begin in a peculiar way more and more to have prominence in Viljanen's symbolism. At the same time, the soil, and the trees that derive strength therefrom retain their central position.

The works of the poet's middle years reveal a striving from the earth upwards towards outer space. On the one hand this appears as an attempt to reach points with a commanding view, on the other as a searching for the aforementioned space symbols.

Even in the poems of his youth there is an attempt to see "wide plains" and expanding views, but it is not until the poem "Näköala vuorelta" (A view from the mountain) belonging to his middle years that visions of eternity are mingled with the picture of expanding landscapes seen from high ground visions in which the universe sighs its vast proclamation of humanity.

In this connection, scholars have drawn attention to the poetry of Giacomo Leopardi, which Viljanen admired as a schoolboy. Viljanen has achieved his clearest striving "towards space" in his tree symbolism, where, remaining firmly attached to the earth's surface he raises the tree tops towards a sighing space. This ambivalent longing for the fruitful soil on the one hand and for the breathtaking expanses of space on the other, unites the dualism of his soul and the tree symbols become a uniting factor in this dualism.

Attention has been drawn to Viljanen's lyrical Janus face which reflects both the life of the soil and the timeless longing of the human spirit for eternity.

The soughing of the winds in the tree tops also symbolizes in Viljanen's poetry a feeling for the whole universe and the youthful poet's fresh experiences of the wind end up in the music of eternity. 
The clouds also symbolize a song which strives to rise free of the schackles of the earth.

The winds and the clouds give Viljanen's poetry a peculiar rhythmical, wave-like motion which makes the images hover between the darkness of earth and the brightness of eternity. The most translucent of Viljanen's space symbols is light, wherein the values of eternity are reflected.

In his well-known poem "Valonpeittämä laiho" (A field full of light), above the grain field trembles this lyrical atmosphere, this soil, from which the poet reaps his own harvest. Viljanen's poetic development was a progression from the earth to the azure of the sky. The soil as a preserver and nourisher of life is the basis of everything, but the poet reaped his harvest in space. 